\title{
Korean Classical Poetry and Song Education in the Revised Literature Textbooks of 2019
}

\author{
So-Yeon Chung1)
}

\begin{abstract}
This study examined the current state of classical poetry education in the 10 types of published literature textbooks of the 2015 revised curriculum. It was confirmed that the content on Goryeo Gayo is the section where active participation, appreciation, and comprehensive inquiry of the learner, which are emphasized in the revised Literature textbooks, are reflected most excellently. In particular, the Goryeo Gayo section was designed to explore the identity of Korean poetry and songs before Hangul and to explore the universality and specialty of Korean literature by comparing it with Chinese poetry or poetry translated into Chinese. By allowing the learners to acknowledge the correlations between Hangul and Chinese texts, spoken and written language, and poetry and songs, this part of literature education is composed very organically to help learners understand the general trends of literary history while comprehensively grasping how the universality of Korean literature as national literature is revealed in classical poetry and songs.
\end{abstract}

Keywords : Poetry, Songs, History, Korean Literary, History, Active, Involvement

\section{Introduction}

The difference between the present and the past of the literature curriculum is an important topic. This study focuses specifically on the education of Korean classical poetry and songs. The proportion of Korean classical poetry and songs included in the curriculum has traditionally been less than that of modern poetry. Aside from the physical amount of time the types of poetry existed in literary history, it is reasonable to expect that the two types of poetry are covered equally. As for the proportion of the works included in the textbooks, however, the number of modern poems covered is much higher than that of Korean classical poems and songs. Considering that Korean classical poetry and songs are given less attention, a survey of the current revised literature textbooks is needed to measure the current interest in and direction of Korean classical poetry and songs, as well as the education of classics in literary education. The revised curriculum's 10 types of published literature textbooks, however,

Received(July 16, 2019), Review Result(1st: August 22, 2019, 2nd: October 21, 2019), Accepted(November 15, 2019)

1) (Professor) 03760 Dept. Korean Education, Ewha Womans Univ., Ewhayeodae-gil 52, Seodaemun-gu, Seoul, Korea

email: chong33@ewha.ac.kr 
have not yet been reviewed, and the discussion of Korean classical poetry and song education has not been addressed at all, making such discussions urgent.

This study explores the current status of Korean classical poetry and songs in revised Literature textbooks. The most interesting question is the way the specialty and universality of Korean classical poetry and songs are addressed and compared with modern poetry. In general, the education of modern poetry mentions only 'poetry,' while that of Korean classical poetry and songs mentions the 'song' as well as 'poetry.' In Korean classical poetry and songs, both poetry and singing are handled at the same time. The role of the song in modern poetry is reduced, or, as its name implies, it completely disappears. Therefore, the element of 'song' should be emphasized in Korean classical poetry and song education. In the curriculum of Literature, the concepts, tradition, character, universality, and specificity of Korean literature always appear. In Korean classical poetry and song education, the universality and specificity of Korean literature have an inseparable relation with this singing. Consequently, I focus on the character of the songs in classical poetry in the 10 types of Literature textbooks.

In classical poetry education, in addition to the characteristics of recorded literature, the singing of classical music, which is enjoyed in oral literature, has recently attracted attention. In particular, the distinctive aspects of the 2015 revised curriculum are the learner's active participation, appreciation, and inquiry, which can be closely linked to the fact that Korean classical poetry and songs were regarded as songs by many people of that era. Park (2018)[1], as emphasized in Sung (1997)[2] and Kim (2016)[3], pointed out that the fact that Korean classical poetry and songs were enjoyed as songs and not as poetry was overlooked in Literature education. Prior to Park's work, Jeong (2013) emphasized that the element of the song should be actively considered in sijo, a genre of Korean classical poetry and songs that is most important in literary education[4]. In Joe \& Jeong (2017), a plan in Goryeo Sokyo education was sought considering the fact that poetry was enjoyed as songs[5].

It is necessary to examine how these findings are reflected in literature education. This is an interesting topic to study in the Literature textbooks, which are assumed to play a central role in literacy education. With this in mind, Section 2 examines the position of Korean classical poetry and songs in the Literature textbooks of the 2015 revised curriculum. Section 3 presents the meaning and complementary measures along with the conclusions.

\section{Overview of Korean Classical Poetry and Songs in 2019 Revised Literature Textbooks}


There are many differences in the content between the previous and revised Literature textbooks on Korean classical poetry and songs. Before discussing the differences, the Korean classical poems contained in the revised texts are as follows:

[Table 1] Korean Classical Poetry and Songs in 2019 Revision Literature Textbooks

\begin{tabular}{|c|c|c|c|c|c|c|c|c|c|c|c|}
\hline & & $\mathrm{D}$ & M & B & $S$ & $\mathrm{~J}$ & $\mathrm{C}$ & $\begin{array}{l}\mathrm{C} \\
(\mathrm{K})\end{array}$ & $\begin{array}{l}\mathrm{C} \\
(\mathrm{J})\end{array}$ & G & $\mathrm{H}$ \\
\hline \multirow{3}{*}{$\begin{array}{l}\text { Ancient } \\
\text { Songs }\end{array}$} & Goo-ji-ga & $\bullet$ & & & ○ & & & & & & \\
\hline & Gong-mu-do-ha-ga & & $\bullet$ & & & & $\diamond$ & & ○ & & $\diamond$ \\
\hline & Hwang-jo-ga & & (-) & & & & & (-) & & & ( ) \\
\hline \multirow{4}{*}{$\begin{array}{c}\text { Hyang } \\
\text {-ga }\end{array}$} & Cheo-yong-ga & $\diamond$ & (-) & & $\diamond$ & & & & & & \\
\hline & Heon-hwa-ga & & ○) & & & & & ○) & & & \\
\hline & Chan-gi-pa-rang-ga & $\diamond$ & $\bullet$ & $\diamond$ & $\bullet$ & & & $\diamond$ & $\diamond$ & $\bullet$ & $\diamond$ \\
\hline & Jae-mang-mae-ga & $\bullet$ & & $\bullet$ & & $\bullet$ & $\bullet$ & $\bullet$ & & & $\bullet$ \\
\hline \multirow{7}{*}{$\begin{array}{c}\text { Goryeo } \\
\text { Gayo }\end{array}$} & Jeong-eup-sa & & & $\bullet$ & & & $\bullet$ & & & & \\
\hline & Dong-dong & & & $\bullet$ & ○ & & & & & & \\
\hline & Ga-si-ri & $\diamond$ & & ○) & $\diamond$ & & & & & & \\
\hline & Cheong-san-byeol-gok & & $\bullet$ & $\bullet$ & & $\bullet$ & () & & & & $\diamond$ \\
\hline & Jeong-seok-ga & & & & $\diamond$ & & & (๑) & (-) & ○ & $\bullet$ \\
\hline & Seo-gyeong-byeol-gok & $\bullet$ & & & $\bullet$ & & & $\bullet$ & $\bullet$ & & $\diamond$ \\
\hline & Jeong-gwa-jeong & & & & & & & & & & $\diamond$ \\
\hline $\begin{array}{l}\text { Gyeong } \\
\text {-gi-chae } \\
\text { ga }\end{array}$ & Han-lim-byeol-gok & & & & & & & (2) & & & \\
\hline \multirow{8}{*}{ Sijo } & $\begin{array}{l}\text { Baek-seol-i man-a-jin } \\
\text { gol-jja-gi-aen (Lee Saek) }\end{array}$ & & & & & & $\bullet$ & & & & \\
\hline & $\begin{array}{l}\text { Chun-san-ae noon nog-in } \\
\text { ba-ram (Woo Tak) }\end{array}$ & & $\bullet$ & & & & & & & & \\
\hline & $\begin{array}{l}\text { Sip-nyeon-eul } \\
\text { gyeong-young-ha-yeo } \\
\text { (Song Soon) }\end{array}$ & $\diamond$ & & & & & & & & $\bullet$ & \\
\hline & $\begin{array}{l}\text { Soo-yang-san ba-ra-bo-myeo } \\
\text { (Seong Sam-moon) }\end{array}$ & & & $\bullet$ & & & & & & & $\bullet$ \\
\hline & Do-san-sib-i-gok (Lee Hwang) & & & & & & & & (1) & & \\
\hline & Go-san-gu-gok-ga (Lee Yi) & & & & & & & & $\diamond$ & & \\
\hline & $\begin{array}{l}\text { Nae ma-eum bae-eo-nae-eo } \\
\text { (Jeong Cheol) }\end{array}$ & & & (2) & & & & & & & \\
\hline & A-chim-eun Bi-o-deo-ni & & & & & & & () & & & \\
\hline
\end{tabular}




\begin{tabular}{|c|c|c|c|c|c|c|c|c|c|c|c|}
\hline & (Shin Heum) & & & & & & & & & & \\
\hline & Eo-bu-sa-si-sa (Yoon Seondo) & & $\bullet$ & & & $\stackrel{\bullet}{(4)}$ & & $\bullet$ & & & $\diamond$ \\
\hline & Man-heung (Yoon Seondo) & $\stackrel{\bullet}{(2)}$ & & $\stackrel{\bullet}{(3)}$ & $\stackrel{\bullet}{(3)}$ & & $\stackrel{\bullet}{(1)}$ & & (2) & & \\
\hline & $\begin{array}{l}\text { Baek-goo-ya } \\
\text { mool-eo-bo-ja } \\
\text { (Kim Cheontaek) }\end{array}$ & & & & & & & & & & $\bullet$ \\
\hline & $\begin{array}{l}\text { Eo-jeo nae il-i-ya } \\
\text { (Hwang Jinyi) }\end{array}$ & $\bullet$ & & & $\bullet$ & & & & & & $\bullet$ \\
\hline & $\begin{array}{l}\text { Dong-ji-nal gi-na-gin } \\
\text { bam-eul (Hwang Jinyi) }\end{array}$ & & & & & & & $\bullet$ & & & \\
\hline & $\begin{array}{l}\text { Moet-beo-deul ga-ryeo } \\
\text { GGeok-eo (Hong Rang) }\end{array}$ & & $\bullet$ & & & & & & $\bullet$ & & \\
\hline & $\begin{array}{l}\text { Lee-haw-woo Heut-bbu-lil } \\
\text { ddae (Gye Rang) }\end{array}$ & & & $\bullet$ & & & & & & & \\
\hline \multirow{8}{*}{$\begin{array}{l}\text { Saseol } \\
\text {-sijo }\end{array}$} & $\begin{array}{l}\text { Na-mo-do dol-do jeon-hyeo } \\
\text { eob-neun }\end{array}$ & & & & & & & $\bullet$ & & $\bullet$ & \\
\hline & Nim-i o-ma-ha-geo-neul & $\bullet$ & & & & & $\bullet$ & & & & \\
\hline & Eo-i mot o-deon-ga & & $\bullet$ & & & & & & & & \\
\hline & $\begin{array}{l}\text { Chang nae-go-ja chang-eul } \\
\text { nae-go-ja }\end{array}$ & & & $\bullet$ & & (2) & & & $\diamond$ & & $\bullet$ \\
\hline & Il-sin-i sal-ja ha-yeot-deo-ni & & & & • & & & & & & \\
\hline & $\begin{array}{l}\text { Han-sum-a ga-neu-da-ran } \\
\text { han-sum-a }\end{array}$ & & & & & & & & $\bullet$ & & \\
\hline & Doo-teo-bi Pa-li-leul mul-go & & & $\diamond$ & & & & & & & \\
\hline & Bal-ga-beot-eun a-i-deul-i & & & & $\diamond$ & & & & & & \\
\hline \multirow{6}{*}{ Ga-sa } & Sang-choon-gok (Song Sun) & & & & & & & $\bullet$ & & & \\
\hline & Sa-mi-in-gok (Jeong Cheol) & & $\bullet$ & & & $\bullet$ & & & & & \\
\hline & Sok-mi-in-gok (Jeong Cheol) & $\bullet$ & & $\bullet$ & $\bullet$ & & $\diamond$ & & $\bullet$ & & \\
\hline & Noo-hang-sa (Park Inro) & & & ( & & & & & & & \\
\hline & Man-eon-sa (An Johwan) & & & & & & & () & & & \\
\hline & $\begin{array}{l}\text { Gyu-won-ga } \\
\text { (Heo Nanseolheon) }\end{array}$ & $\diamond$ & & & & & & & & $\bullet$ & $\bullet$ \\
\hline $\begin{array}{l}\text { F o } 1 \mathrm{k} \\
\text { Song }\end{array}$ & Jeongseon arirang & & & & $\diamond$ & $\bullet$ & $\diamond$ & & $\bullet$ & & \\
\hline \multirow{5}{*}{ Hansi } & $\begin{array}{l}\text { Jae-ga-ya-san-dok-seo-dang } \\
\text { (Choi Chiwon) }\end{array}$ & & • & & & & & & & & \\
\hline & Chok-gyu-hwa (Choi Chiwon) & & & & & & & & $\bullet$ & & \\
\hline & $\begin{array}{l}\text { Choo-ya-woo-joong } \\
\text { (Choi Chiwon) }\end{array}$ & & & & & & & & & & $\diamond$ \\
\hline & Song-in (Jeong Jisang) & (0) & & & & $\bullet$ & $\diamond$ & & & & $\diamond$ \\
\hline & So-ak-boo (Lee Jaehyeon) & & & & & & & (0) & & & \\
\hline
\end{tabular}




\begin{tabular}{|l|l|l|l|l|l|l|l|l|l|l|}
\hline Yo-yang-eui dal (Heo Gyun) & & & & & & & ( & & & \\
\hline Sa-chin (Kim Manjoong) & & & & & & & & $\diamond$ & & \\
\hline Bo-ri-ta-jak (Jeong Yak-yong) & & & & & & & & $\bullet$ & & \\
\hline $\begin{array}{l}\text { Tam-jin-chon-yo } \\
\text { (Jeong Yak-yong) }\end{array}$ & & & & & & & & & & $\diamond$ \\
\hline $\begin{array}{l}\text { Jeol-myong-si } \\
\text { (Hwang Hyeon) }\end{array}$ & & $\bullet$ & & & & & & & & \\
\hline Dong-gok-chil-ga 4 (Tu Fu) & & & & & & $\bullet$ & & & & \\
\hline Choon-mang-sa (Seol Do) & & & & & & & & $\bullet$ & & \\
\hline
\end{tabular}

D: Dong-A, M: Mirae-en, B: Bisang, S: Shinsago, J: Jihaksa, C: Changbi, C(K): Cheonjae (Kim), C(J): Cheonjae (Jeong), G: Geumseong, H: Haename-Edu

: main works, (O): student activity works, $\diamond$ : others, 0 : the numbers of the same title's work

In the previous curriculum, Sijo was emphasized as the most representative genre of Korean classical poetry and songs, while in the revised curriculum, the number of works by genre is more balanced. Assuming that Saseol-Sijo is included in Sijo, Sijo is the most common type of Korean classical poetry and song. However, all textbooks sought to refer to each genre though the specific works are not contained in the text. The reason that the proportion of Sijo was overwhelmingly high in the past is not only because of the fact that Sijo is a national genre representing Korean classical poetry and songs, but also that the number of Sijo works handed down is much higher than that in other genres. A comparison with Goryeo Gayo, which has a relatively small number of available works, shows that the prejudice toward Sijo is weakened in the revised textbooks, as there are a similar number of works of Sijo and Goryeo Gayo in each textbook, around 3-4 pieces.

In addition, learning activities related to sijo in the revised curriculum are not much different from those in the former curriculum. As the number of works in textbooks is reduced, only the representative works are covered. The activity part, therefore, follows the past method that focuses on the content that should be handled in sijo such as formal beauty and charging groups. The learner's appreciation and active and voluntary participation are somewhat more emphasized, though no significant change in the Literature parts with the revision of the curriculum is found. Even this finding, however, is shown not to be reflected in the activities of sijo education.

For the Ga-sa genre, the strong bias remains because, as with Pyeong-Sijo, the works from the late Choseon period are not addressed. The late Choson period is important because the changes in classical poetry and songs in this period, such as the expansion of charging groups to include anonymous or common people's works and the diversification of themes, are linked 
to the history of the novel. However, the most recent works addressed in the textbooks are those from the early Choson period, a disappointing fact.

A genre that is addressed relatively more in the revised curriculum compared to the past is Goryeo Gayo. In addition to the adoption of more works than the Pyeong-sijo, activities to deepen the learner's thinking, inquiry, and active participation are strengthened. The level of activity is high enough to link it with the first year of university. The fact that the Goryo Gayos were translated into the Chinese letter in the <So-ak-boo> presents the opportunity to examine the way changes in literary history evolved in terms of the relation between Hangul and Chinese letter literature (Kim, Cheonjae, 2019). The continuity of literary history can be addressed through the association between ancient Gayo and Goryeo Gayo (Jeong, Cheonjae, 2019)

It is also noted that the emphasis is on the genre as a song, especially in the Koryo Gayo activity section. In addition to deepening the inquiry of literary history, the fact that ancient Gayo and Koryo Gayo are linked to current popular songs (Jeong, Cheonjae, 2019) allows literature education as an activity of the 'Korean language' not only to go beyond just Chinese and Hangul texts but also to establish the study of Korean literature across the ages. Also, types of Chinese poetry, <Song-in> and <Seo-kyeong-byeol-gok>, are addressed together, enabling the activity to include the creation of lyrics (Dong-a, 2019). It also provides an opportunity to think about whether classical poetry and songs expanded their territory and played a unique role despite the position of poetic literature being rigid and the absence of Hangul. In addition, beyond learning about past literature, students of the revised curriculum gain an awareness that current song lyrics are very much poetry, and thus, they can explore the association between songs and poetry.

In the case of folk songs, although only <Jeong-seon-a-ri-rang> is covered in several textbooks, the topic garners attention because of its special meaning. Two textbooks using this topic as their main theme are addressed in the works 'Status and Development of Korean Literature' (Jihaksa, 2019) and 'Past, Current, Future, Expansion, and Development of Korean Literature' (Jeong, Cheonjae, 2019). In addition, even when this is dealt as another resource, "Jeongseon Arirang" is presented in "Changes and Development of Korean Literature." (Genesis, 2019). These works have the commonality of looking at the future beyond the past and current time.

The name of this unit was not found in the past curriculum, and it has the strength of considering not only literature's past and present but also its future (Jeong, 2017). Through Arirang, which is on the UNESCO World Heritage list, the learners have the opportunity to 
explore the identity and universality of Korean literature in world literature and at the same time appreciate the uniqueness of local literature and create lyrics for their Arirang, inducing the participation of learners. In other words, through the characteristics of Korean classical poetry and songs and the combination of the active participation of learners and comprehensive thinking, classical poetry and songs show that folk songs can deepen and expand the breadth of education. Many implications are suggested because classical poetry and songs, which have a long tradition as folk songs, are rather important in exploring the future of literature based on various regional changes while showing the universality and globalization of Korean literature.

\section{Conclusion}

This study examined the current state of classical poetry education in the Literature textbooks of the 2015 revised curriculum. It was confirmed that the content of Goryeo Gayo is the part where active participation, appreciation, and comprehensive inquiry of the learner, which are emphasized in the revised curriculum, are reflected most excellently. In particular, the Goryeo Gayo section was designed to explore the identity of Korean poetry before Hangul and to explore the identity of Korean literature by comparing it with Chinese poetry or poetry translated into Chinese. Allowing the learners to acknowledge the correlations between Hangul, Chinese text, spoken and written language, and poetry and song, this part of the curriculum is composed very organically to help learners understand the general trends in the history of literature while comprehensively grasping how the universality of Korean literature as national literature is revealed in classical poetry and songs.

In classical poetry and song education, therefore, the attributes of poetry and song and the relationship between their characteristics should be considered. The examination of the position of the song in modern poetry will play an important role in enjoying and observing trends in the history of literature, the current viewpoints, and the future. By linking the achievements made in Goryeo Gayo to not only sijo but also modern poetry education, learners should be encouraged to participate more actively in their literary education as well as comprehensive and deep thinking activities.

The direction of the revised textbooks that focus on the characteristics of songs is an important change in that it coincides with the direction of the revised curriculum, in which active participation, comprehensive thinking and appreciation of learners are emphasized more than work-oriented knowledge. These revised directions are reflected, related to the song, in the 
revised literary textbooks.

For example, through the activities that induce learners to understand that Goryeo Gayo was a song, to notice that, before the development of Hangul, the transformation of genres was sought by using the $\langle\mathrm{So}-\mathrm{ak}-\mathrm{bu}\rangle$, a song translated into the Chinese language, and to consider the range of Korean literature in both the written and spoken languages, the revised curriculum leads them to comprehensively explore the universality of Korean literature by linking it to the problem of the language medium and genre. Since Goryeo Gayo such as <Ga-si-ri> has actually been reborn in more than 30 popular songs (Yeom, 2012), the phenomenon that has already appeared should be more actively reflected in the field of education. In addition, through the activities of singing classical poetry and songs or the lyrics written by the learners themselves on the borrowed melody of popular songs, the song is melted into the field of literary education.

By confirming, through this process, that the characteristics of the song stem from classical poetry and that the continuous phenomenon is related not only to modern poetry but also to the contemporary song, learners should be encouraged to think about the specificity and universality of Korean literature. This provides an opportunity to recognize that the scope of Korean literature is not limited to recorded literature but also extends to oral literature. These activities are likely to enable learners to understand that classical poetry and modern poetry have a continuous and integrated nature, which may nurture their open-mindedness to build upon the universality of Korean poetry.

For example, in the case of folk songs, all textbooks carry only <Jeong-seon Arirang>. This has significance in that the newly found Ariraing, not the well-known ones of Seoul or Gyeong-gi, is introduced. It should be noted that the reason why Arirang is on the UNESCO World Heritage list is that Arirang has an infinite variety that can be found everywhere Koreans are. The fact that all of the textbooks in Arirang contain only one specific piece of work requires an inventory. Considering the educational significance of Arirang, which is representative of both world cultural heritage and local characteristics in this global era, it is necessary to compare Arirangs in various regions and to examine local folklore as well Arirang. The present text of <Jeong-seon Arirang> occupies more than one page, which is enough space to include Arirangs of various regions.

The problem of variety is found not only in folk songs but also in classical poetry. The melody is determined by the singer at the moment without a fixed one. This is why classical poetry is user-centered and possessed by all people. Actively practicing the characteristics of classical poetry and recreating them into many varieties according to the learners' locality or 
internal emotions presents an opportunity for them to be the poetry of this era. Since these activities enable the connection of the singularity of classical poetry to modern poetry and the learners are provided with the opportunity for active participation, appreciation, and comprehensive inquiry, they reflect the direction of the revised curriculum and at the same time are a good way to supplement the biased aspect of education.

Finally, it is necessary to apply the movement of reading one book, emphasized in the revised curriculum, not only to novels but also to poetry. In the case of classical poetry and songs, the works are published in a later generation's literature due to the limitations of the recording medium. It is essential, therefore, to examine the context in which each work is included. The current textbooks are not able to deal with this phenomenon because they employ an approach based on fragmented works. In particular, works such as classical poetry and songs are rarely introduced fully, and most of them are excerpts, which is also true for Yeon-sijo. Though it is reasonable to exclude classical poetry and songs that are too long (2015 revised curriculum, p. 128), the movement of reading one book should be extended to include classical poetry and songs.

\section{References}

[1] G. J. Park, Importance of Enjoyment Method in Classic Poetry Education and its Methodological Study, The Classical Literature and Education, (2018), No.38, pp.5-35, DOI: 10.17319/cle.2018..38.5

[2] H. G. Seoung, The Way of Presence and Songs of Korean Classical Poetry, Korean Classical Literature Study, (1997), Vol.12, No.1, pp.59-89.

[3] H. S. Kim, Singing tradition of pre-modern poetries and Songs, and Free Verse of Contemporary Poetries, Korean Classical Poetry Studies, (2016), Vol.41, pp.5-30, DOI: 10.32428/poetry.41..201611.5

[4] S. Y. Chung, The Manners of Emotion Expression in Sijo of Orality and Direction of Sijo Education, The Classical Literature and Education, (2012), No.24, pp.97-124, DOI: 10.17319/cle.2012..24.97

[5] E. J. Cho and S. Y. Chung, A Study on Goryeo-sokyo Education Considering Performance Field, Asia-pacific Journal of Multimedia services convergent with Art, Humanities, and Sociology, (2017), Vol.7, No.2, pp.891-898, DOI: 10.35873/ajmahs.2017.7.2.084 